Conference Paper

\title{
Flight Attendant Training Program Evaluation Based on Kirkpatrick Model
}

\author{
Chandra Sagul Haratua Gultom*, R. Komala, Maruf Akbar \\ University Negeri Jakarta, Indonesia
}

*Corresponding author:

E-mail: chandra.sagul@gmail.com

\begin{abstract}
Training evaluation is an activity that must be carried out so that companies can believe that the training they provide can have a positive impact on improving employee performance and the company as a whole. One of them is the Flight Attendant training program at the Angkasa Training Center (ATC). The specific purpose of this research is to evaluate program implementation starting from the reaction, learning, behavior, and results which include: evaluation of program effectiveness, evaluation of program implementation, and evaluation of the impact of the program itself. Data were obtained through interview instruments, and Focus Group Discussion (FGD) through qualitative descriptive techniques. Interviews were conducted with flight attendant students, training participants' bosses, and fellow trainees, namely flight attendant students. The results of this study indicate that 1). Reaction evaluation, namely the results of reactions from students to the organizing committee and resource persons is very high. Only need to pay attention to the preparation of materials at the beginning of the training, 2). Learning evaluation, namely the ability of the competence of attitudes, knowledge, and skills of students to have a very significant assessment, 3). Behavioral evaluation, namely the implementation of the evaluation is carried out after the participants return to their respective workplaces. There was a significant increase in a behavior change from before training and after training. Behavioral changes such as attendance discipline, dress code, walking, motivating peers, good communication, and accuracy and speed in completing daily tasks, 4). Impact evaluation, namely there is an increase in the work of training alumni. Alumni can educate and guide and apply the knowledge gained from training to their peers, able to develop better training methods
\end{abstract}

Keywords: Evaluation, program, flight attendant training, and Kirkpatrick's fourlevel model

\section{Introduction}

According to Cross and Daniel (2018), Effective training is training that can achieve an organizational goal, increase the ability of resources, and satisfy consumers and improve internal processes. Knowledge is a reliable source to deal with turbulent, uncertain, and complex global environments. Knowledge provides a competitive advantage. Complex business challenges have to be answered easily with special and selective knowledge gathered during training. This is the reason almost all companies are paying more attention to training. About winning the business competition, evaluation of training effectiveness is important considering the learning outcomes of training can produce knowledge, abilities, and attitudes possessed by cabin crew in conducting flight services. In addition, the effectiveness of the training carried out to provide knowledge, abilities, and attitudes in the form of behavior that reflects service during the flight is also influenced by psychological factors such as individual goals, individual learning, individual needs, and reinforcement received, while the non-psychological factors are: facilities, materials and instructor teaching methods.

Lion Air Group has an integrated area in the Balaraja area, Banten. The area is called Lion City Lion City stands on an area of 30 hectares. At that location, there are office areas, Angkasa Training Center

\section{How to cite:}

Gultom, C. S. H., Komala, R., \& Akbar, M. (2021). Flight attendant training program evaluation based on kirkpatrick model. $1^{\text {st }}$ ICEMAC 2020: International Conference on Economics, Management, and Accounting. NST Proceedings. pages 352-361. doi: $10.11594 /$ nstp.2021.1040 
(ATC), housing for flight attendants for Lion Air Group. At that location, there are two buildings that have 92 rooms. At the training location itself, there are several facilities ranging from classrooms, mockups of Boeing 737 aircraft equipped with various emergency doors and swimming pools that are used by prospective flight attendants to carry out rescue simulations on water. After going through the training phase in class, the flight attendants were directed to go to a mock-up to immediately practice evacuating the aircraft passengers. The training starts from opening the emergency door to the correct way to launch the emergency door. In the next stage, prospective flight attendants were directed to the edge of the swimming pool to be explained how to develop an inflatable boat, to how to board a boat.

At the Angkasa Training Center, Lion Air Group flight attendants are trained in their ability to serve passengers on the plane. To become a flight attendant in the Lion Air Group, participants must attend a series of training for 3 to 4 months. At the Angkasa Training Center, there are several facilities, ranging from classrooms, aircraft mock-ups, and a swimming pool area for emergency training.

This emergency training is carried out in four stages, starting from classroom training, training to extinguish fires, conducting land rescue, and performing a rescue in water. Flight attendants are required to understand the process of rescuing passengers in an emergency.

In the first stage, the flight attendants are given an understanding and introduction to how to use the safety equipment on board. They are also taught how to put out a fire in case of a fire on the plane. Furthermore, they were given training on how to open and exit through emergency doors. To get out of the emergency door, the flight attendants are taught how to slide properly. Then, they are also taught how to evacuate passengers when they are in an emergency in the water. In that phase, they are taught how to develop and ride a rubber boat.

They were also taught how to inflate a buoy in 10 seconds. After that, they were taught how to evacuate passengers when in a water emergency, including how to deal with underwater animals such as sharks. They must know how to get passengers into the rubber boat, and how to survive on the sea. After practicing the procedures when facing an emergency, the flight attendants are asked to return to the room for an evaluation.

This emergency training is not only given to prospective flight attendants. Experienced flight attendants are required to participate in this training regularly. Those who are already flight attendants, they still follow this exercise. Usually done once a year. Lion City has a mess of 1,966

Kirkpatrick's evaluation model was specific to this training program, although it can also be applied to other disciplines. The four stages that Kirkpatrick means are very important and must be understood by professionals in the fields of training, development, and education to see what is planned, what is coordinated, and how the process is applied, also to see how the participants are, and how it is implemented. the program (Kirkpatrick \& Kirkpatrick, 2005).

The four-level Kirkpatrick evaluation model includes evaluation of reaction, learning, behavior, and results. Reaction evaluation aims to measure how participants react to the program, for example, participant satisfaction. The information needed in the evaluation of the reaction is a good reaction from the participants because the bad reaction makes the participants not motivated to learn. Learning evaluation aims to obtain information about learning for changing attitudes, increasing knowledge and skills as expected after participating in a training program. Behavior evaluation aims to see the four conditions of student behavior change which are initiated by a desire to change, knowing what and how to do it, working in the right climate, and strengthening the existence of these changes. Outcome evaluation aims to measure the outcome of the training program because the ultimate goal of the training program must be stated in this outcome evaluation.

\section{Literature Review}

According to Nda and Fard (2013) has presented a new point of view of training, according to him, previously training was considered to be an expenditure, but now it serves as a role of investment activity. The organizations follow a modernization. To cope with this, organizations need employees with updated skills \& knowledge, and this can be done through training. According to Vlad and Stan (2013) that organizations do not run in isolation or not only face local challenges but they work with different 
multinational organizations, and these multinationals bring global competitive culture and environment which affects the local economy and operating business entities. He also stated that training \& development not only improves the individual capabilities or skills but also the whole team and overall organization. Training advances the individual skill which helps in improving his performance in an organization as a result organizations effectiveness improves in society or in general. Thus, the training of employees plays a key role in enlightening the organization's performance, well-being, profitability in a society. Individual training results in the organization's effectiveness. Training is for improving, enhancing, and updating the skill, knowledge \& abilities to perform better. As challenges of the external environment increase day by day which ultimately affects the internal customers as well (Ontorael \& Suhadak, 2011). And planning put effectiveness in training, along with this participant's selection, administrative support, venue, moderator or facilitator, and contents of training. Training means equipping employees with new or traditional methods or techniques or modules to translate information, knowledge \& skills to practice in an organization to improve the overall effectiveness of the organization. Training is for the current stage and development is for the future stage. Training is a part of the prime objective of an organization. In some organizations learning culture is their social responsibility. From the various study, it has been found that there is a link between organizational performance and training. Training has a strategic contribution to organizational goals. The training plays a vital role by contributing to the nation's human capital. Training directly contributing to employees career development Organization focus on key position's career development but according to him, the organization must emphasize on the fresh employee for their high ranking position in future, so that against organization's this effort guaranteed loyalty, commitment, sincerity with the same organization. This is not a written agreement but rather an emotional \& psychological commitment. To tackle with financially competitive $\&$ dominant market. As the business environment is continuously fluctuating due to haphazard changes in taste, preferences, lifestyle, more advanced needs, to embark upon these conditions organization must have competent and well-equipped employees. This equipment of talent material and skills is incorporated in employees through training programs.

According to Gronlund, evaluation is a systematic process for determining or making a decision and to what extend objectives or programs have been achieved (Gronlund \& Linn, 1990). The evaluation is a process used to assess (Kaufman \&Thomas, 1980). Scriven defines evaluation as quoted by Fitzpatrick, Sanders, and Worthern (2004), "Evaluation as judging the worth or merit of something. Training is for improving, enhancing, and updating the skill, knowledge \& abilities to perform better. As challenges of the external environment increase day by day which ultimately affects the internal customers as well.

For better result organization should invest in improving hard and soft types of skills. In addition to this, Djaali and Muljono (2008) define evaluation as the process of evaluating something based on standards or objectives that have been set and then followed by decision making on the object being evaluated. And planning put effectiveness in training, along with this participant's selection, administrative support, venue, moderator/facilitator, and contents of training. On the other hand, Pasban and Nojedeh (2016) stated that training plays a vital role by contributing to the nation's human capital. All training design, need analysis, implementation \& evaluation has been done by the HR department. As HR is the policymaker, they design policy for the betterment of the company's performance, and now training has become one of the parts of HR policy. Because it directly contributes to employee performance, which leads to overall organizational performance (Diamantidis \& Chatzoglou, 2018).

Training directly contributing to employees career development Organization focus on key position's career development but according to him, the organization must emphasize on the fresh employee for their high ranking position in future, so that against organization's this effort guaranteed loyalty, commitment, sincerity with the same organization. This is not a written agreement but rather an emotional \& psychological commitment. To tackle with financially competitive \& dominant market. As the business environment is continuously fluctuating due to haphazardly changes the taste, preferences, lifestyles, more advanced needs, to embark upon these conditions organization must have competent and well-equipped employees. This equipment of talent material and skills is incorporated in employees 
through training programs. It was further explained that "Evaluation is the identification of clarification and application of defensible to determine an evaluation object's (worth and merit) to those criteria (Fitzpatrick et al, 2014). From this description, it can be concluded that the evaluation is essentially an effort to assess whether the results of the program carried out following existing criteria. Training is a part of the prime objective of an organization. In some organizations learning culture is their social responsibility. From the various study, it has been found that there is a link between organizational performance and training.

Furthermore, the Joint Committee on Standards for educational evaluation defines program evaluation as an educational and training activity that provides service continuously and often involves curricular offerings.

\section{Material and Methods}

In general, this research is to assess and obtain information about program effectiveness, evaluation of program implementation, and evaluation of program impact. This information is used to make alternative decisions and recommendations for the development, improvement, and refinement of the Initial Flight Attendant Training Program at the Angkasa Training Center (ATC). As evaluative research, this study aims to explain the components that support the effectiveness and development of a program. The method used in program evaluation research uses the Kirkpatrick model. The type of research used in this research is the type of quality research. This research is fundamental and is interrelated with the relationship between Reaction, Learning, Behavior, and Outcomes with the Effectiveness of the Initial Flight Attendant Training Program. Fundamental is a concept that describes an event, and the circumstances that must be accounted for and communicating to interested parties.

The data collection technique in this study was carried out through a Focus Group Discussion (FGD), which is a data collection technique that is generally carried out in qualitative research. Focus Group Discussion is usually conducted at the evaluation stage of training levels 2,3 , and 4 where the Focus Group Discussion can dig up information that comes not only from one person.

\section{Results and Discussion \\ Reaction Level}

The level of reaction is a program evaluation of the training students' dissatisfaction with the various activities that have been followed. Student reactions can determine the level of achievement of a goal rather than the training administration. The training implementation program is said to be successful if the training students are satisfied with the elements involved in the implementation process. The success of the learning process cannot be separated from the interest, attention, and motivation of the training students in participating in the training. Students learn better when they react positively to the learning environment. The reaction instruments in evaluating the reaction level are:

a. Student reaction to administration. The aim is to find out the training student's satisfaction with the success of the learning activity process, which is inseparable from the interest, attention, and motivation associated with membership, the committee, accommodation, curriculum, consumption, and training facilities.

b. Student reactions to sources. The aim is to determine the satisfaction of training students with the learning process that is assessed from several aspects, such as the material provided, the facilities available, and the sources. 


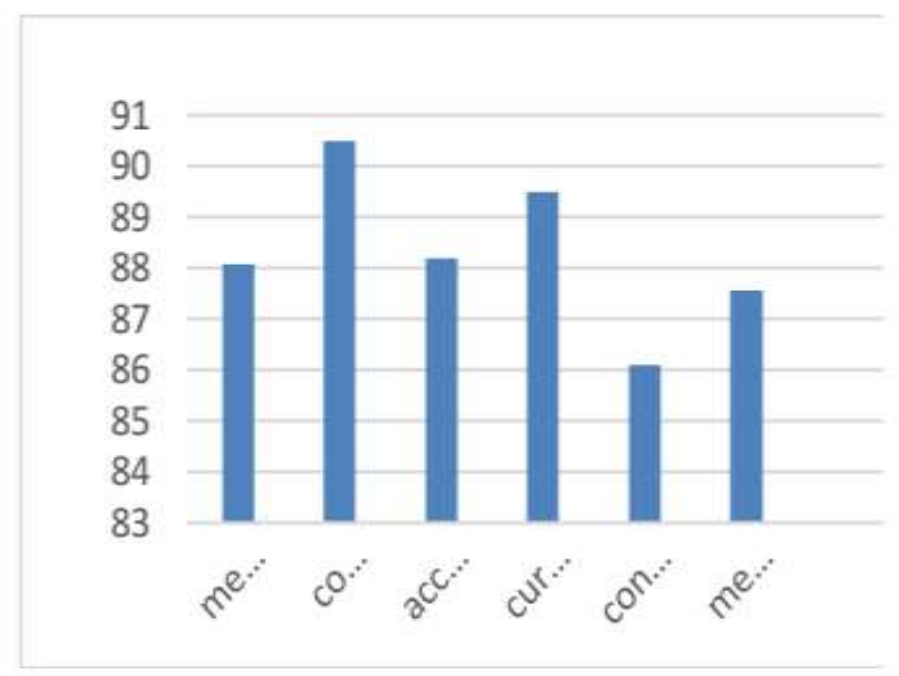

Figure 1. Reaction level

The results of the assessment of the student's evaluation of the organizing committee on the components and average scores are: (a). participation (student discipline) 88.10; b). committee (service, discipline, cooperation with participants, service to resource persons, and attitudes towards resource persons) 90,50; c). accommodation (cleanliness and comfort) 88.30; d). curriculum (training schedule, training materials, training material benefits, and extracurricular activities) 89.50; e). consumption (menu and presentation) 86.10, and f). training facilities (classrooms, aids, and learning materials) 87,50. The average result of the overall evaluation of student reactions to the organizer was 85.7, including the "Good" category. Based on the evaluation of students' reactions to training, it can be said that it is effective. However, some are of concern or not following student expectations, namely consumption, the availability of teaching materials, and computers so that students do not need to move seats in completing their assignments. Based on the results of observations in the field, it is found that students are quite active every session. However, there were a small number of students who looked sleepy in several sessions presenting the material, perhaps because of the coming month of Ramadan. Students are always present in every session and they are active in participating in the material presentation session. The results of the interviews indicated that students were generally quite enthusiastic about participating in the Flight Attendant training program at the Angkasa Training Center, Jakarta.

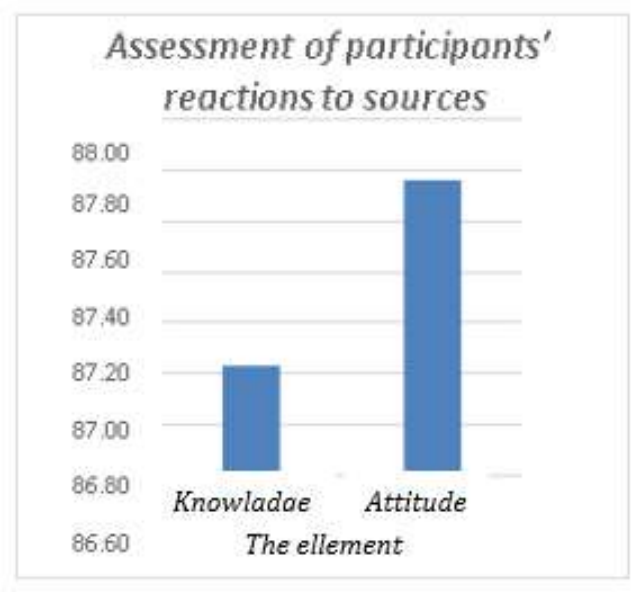

Figure 2. Assessment of participants' reaction to sources 
The results of the research from the students' evaluation of the resource persons in the "Good" score were proven by the overall average score of 88.37 . There were 2 resource persons, namely Ms.Wina The components that are assessed are:

a. In terms of knowledge, which includes the following indicators: Teaching knowledge and skills, mastery of the material, presentation systematics, use of methods, and learning aids. The average value obtained is 87.03 .

b. Attitudes include the following indicators: ethics, attitudes, towards participants, how to answer participant questions, how to communicate, give motivation, time discipline, skills in dress, how to walk, and cooperation (Team). The average value obtained is 87.76 . So, the overall student assessment of resource persons is 87.40 and is included in the "Good" category.

Based on the results of interviews with students, data was obtained that the resource persons not only explained in theory about designing learning programs but also with examples that were applied through teaching practice in class.

\section{Learning level}

At the learning level, evaluation of learning outcomes is carried out, namely the achievement of learning objectives and learning outcomes that are expected from a learning process. The learning outcomes that are tested must be following the learning subjects taught and the objectives of the learning process in the Flight Attendant training program at the Angkasa Train-ing Center, Jakarta.

In measuring the effectiveness of learning, three aspects need to be measured, namely: attitudes, knowledge, and skills. At the learning stage, it is hoped that changes will occur from program students in these three aspects and following the objectives of the training program. Without a change in attitude, an increase in knowledge, or an improvement in skills in students, the program can be said to be a failure. Measurement of learning outcomes (learning measurement) is as follows: a). change of attitude, b). the knowledge that has been learned, and 3). Improved skills. Determination of graduation of training students based on evaluations carried out during the evaluation process of the implementation of the initial flight attendant training program at the Angkasa Training Center Jakarta is carried out from several aspects, namely: a). assessment of student attitudes by $30 \%$, b). assessment of student knowledge by $40 \%$, c). assessment of student skills by $30 \%$. The determination of graduation qualifications for initial flight attendant training students at the Angkasa Training Center, Jakarta which is carried out by the organizing committee and resource persons from the Directorate of Airworthiness and Air-craft Operations (DKUPPU) is above 76 (seventy-six). Evaluation at the learning stage aims to measure the level of students' understanding of the learning material or the extent to which students absorb the flight attendant training program at Angkasa Training Center Jakarta on the material provided in terms of attitudes, knowledge, and skills. The flight attendant training program is said to be successful if the three aspects have improved by comparing the measurement results before and after the learning process.

Training program students are judged by the organizing committee and resource persons in 3 (three) aspects, namely

a. Assessment on aspects of attitude

Instruments that are assessed include: 1). Behavior (honest, respect for differences, friendly, and empathetic): 90,25; 2). Discipline (dress following the provisions in the guidelines, seriousness in learning, and comply with learning commitments: 89,75; 3). Attendance 89,75,4). Initiative (giving ideas or ideas in groups, providing solutions to each problem, and motivating group members) 86; 5). Cooperation (active in completing group assignments, being cooperative with resource persons/committees in implementing the program) 85.75; 6). Participation (actively asking, actively answering, actively responding, actively spearheading the implementation of group tasks and motivating group members) 89,63; and 7). Responsibility (carrying out tasks, having the courage to take risks, maintaining class order, and maintaining the good name of individuals, classes, groups, and institutions) 86,25 . The result of the average assessment of students was 88.00 and categorized as "Good". 
b. Assessment on aspects of learning Name of Pre-test Postest Average 44.60 85.40

Assessment of the learning aspect is carried out through a written test, which is to measure the increase in knowledge by carrying out the initial test and final test. From the acquisition of the initial test results an average of 44.60 and the final test an average of 85.40. It appears that there is a significant increase in the competence of students' knowledge so that it can be categorized as "Good".

c. Research on the aspects of skills

Namely, assessment through teaching practice (micro-teaching), such as mock-up teaching, cabine process, announcements, and service dialogues. This assessment was carried out to determine the achievement of the competence of the flight attendant students in applying their duties, and the results of the assessment on the skills aspect were 86.13 categorized as "Good".

At the behavior level, an assessment of the alumni of the flight attendant training program at the Angkasa Training Center Jakarta is conducted to determine changes in behavior after attending training and returning to their respective assignments. Based on the results of interviews that have been conducted, it was found that alumni showed very significant changes. These changes occur in discipline, attendance, student appearance, independence, attitudes in teamwork or in groups that are more cooperative, as well as speed and accuracy in completing tasks more quickly and on time, all of which have had very good chances. The level of discipline was good before joining the training, but some had not changed after the training.

In reviewing the results of interviews with students, it was clear that students were very enthusiastic and their behavior got better. It can be said that the actualization task given to students of the flight attendant training program at the Angkasa Training Center Jakarta is fully carried out. Various responses and behavioral indicators in the flight attendant work unit can be categorized as good, meaning that after flight attendant training at the Angkasa Training Center Jakarta, students can carry out their duties according to actualization tasks.

\section{Impact level}

The evaluation of the training program aims to get good results, such as an increase in quality, productivity, or level of safety. Evaluation at the impact level aims at whether the training program is useful in achieving company goals. The final result of the impact evaluation is customer satisfaction (customer satisfaction), an increase in student flight attendant work. Evaluation of the impact of training is focused on: a). cost reduction, b). decreased turnover and coworker absence, and c). increased student morale. As a student or alumnus of a flight attendant training student at the Angkasa Training Center. Guidance and direction from alumni to peers is needed, not only for the addition of knowledge but also for improvement, especially in terms of learning and behavior.

The results of interviews with program instructors and students with alumni showed clearly the impact of the initial flight attendant training program at the Angkasa Training Center. The effectiveness of Kirkpatrick's model training program is to measure the extent to which training affects the achievement of the training program objectives which impacts the achievement of individual goals for the place of duty.

In creating a program it must be based on needs (need analysis), the point is that training is an important investment in strategies that lead to internal promotion, employee planning sequences. Need assessment is not a result but a specific activity in making certain decisions. Needs analysis is a constructive and positive tool in making changes, such as changes based on rational logic, functional changes that can meet the needs of groups and individuals. Need analysis is a way or method to find out the difference between the conditions you want / should (should be / ought to be). Training needs analysis can be divided into three parts, namely: (1) analysis at the organizational stage where training can and should be carried out. The focus is on the company as a whole and the analysis is related to the objectives of the company, its effectiveness indicators, and the company's organizational climate; (2) analysis at the job level using data collection. The analysis will determine what standards are needed, what knowledge, skills, and attitudes are needed to achieve these standards; (3) focus on the person / personal analysis. Personal analysis was conducted to answer the question: who needs training? And what kind of training will you do? For that, it takes time, to make a complete diagnosis of each employee's ability. Efforts need to be made to obtain this information through achievement tests, observations, and interviews. Needs analysis is a 
scientific activity in identifying supporting and inhibiting factors (gaps) in the learning process to achieve learning goals (goals and ob-jectives) which lead to improving the quality of student flight attendant learning. The Need As-sessment method is designed to be able to measure the level of gaps that occur in student learn-ing from what is expected and what has been obtained. Need Assessment is carried out in stages including preparation, data collection, data analysis and interpretation, dissemination, and report preparation. According to Morrison, the function of need assessment is as follows:

a. Identify needs that are relevant to the current job or task

b. Identify urgent needs related to financial, security, or other problems that interfere with the work and learning environment of flight attendant students.

c. Presenting priorities in choosing an action (reaction).

d. Provide base data to analyze the effectiveness of flight attendant student learning.

While the steps of the need assessment are as follows (Morrison, 2011):

a. Planning, what needs to be done is to classify the flight attendant students, who will be involved in the activities, and how to collect them.

b. Data collection, what needs to be done is to consider the size of the sample in the distribution (spread).

c. Data analysis, what needs to be done is to collect data and then analyze it with consideration of their needs.

d. Making a final report, including objective analysis, process analysis, analysis of results using tables, and recommendations related to data.

e. Formulate objectives following the training (Set learning objectives).

The benefits obtained from a training held by the company are as follows:

Development programs are planned to provide benefits to people in the form of increased productivity, increased morale, reduced costs, and stability and flexibility (flexibility) of the greater person to adapt to changing external requirements. The success of a training program is determined by five components, namely:

a. Training or development goals: every training must have clear objectives that can be broken down into observable and measured behaviors to know the effectiveness of the training itself.

b. Trainer (Trainer): the trainer must be able to teach training materials with a certain method so that the participants will acquire knowledge of the skills and attitudes needed following the set sasaian).

c. Exercise materials: training materials must be arranged based on the established training objectives

d. Training methods (including tools): After the material from the exercise is determined, the next step is to formulate an appropriate training method.

e. Participants (Trainees): Participants are a fairly important component because the success of a training program also depends on the participants.

f. Another goal is meaningful as a goal, both aimed at organizations and community groups, namely emphasizing the success of a program in the short term that we can manage. In training, it is more often referred to as specific learning objectives, for example: after completing a prime subject or certain skill the participants can formulate the meaning of excellent service and be able to carry it out.

\section{Make a program schedule according to the time needed (Schedule the program at the right time)}

A program schedule is a timetable showing work in a project, program, or portfolio. Schedules can be made for different aspects of the job and there is an understanding of important communication with all team members and stakeholders.

The objectives of program schedule management are 1) to determine the time scale in work, 2). Calculating the profit demand for resources, 3). Shows schedule reports in a format suitable for different stakeholders. Scheduling starts with the identification and definition of the work that must achieve the goals. The factors that influence the way the schedule is presented are as follows:

a. The level of detailed scheduling requested.

b. Should the schedule information be combined with resource information and/or the scope of the work context, hearings for information 


\section{The program location must be in accordance with the time and place of training (Hold the program at the} right place with the right amenities)

The implementation of the program is situational in the sense that the calculation of organizational interests and the needs of the participants may differ in accentuation and intensity which is ultimately reflected in the use of techniques in the learning process. Implementing training and development programs in principle carrying out the teaching and learning process means that there are trainers who teach a subject. Therefore, whether or not a teaching technique is appropriate depends on the highlighted considerations, such as savings in funding, available materials, and facilities, the ability of participants, the ability of the trainer, and the learning principles used.

The implementation of the program is situational in the sense that the calculation of organizational interests and the needs of the participants may differ in accentuation and intensity which is ultimately reflected in the use of techniques in the learning process. Implementing training and development programs in principle carrying out the teaching and learning process means that there are trainers who teach a subject. Therefore, whether or not a teaching technique is appropriate depends on the highlighted considerations, such as savings in funding, available materials, and facilities, the ability of participants, the ability of the trainer, and the learning principles used. Placement of work personnel within the scope of an organizational unit greatly determines the continuity of employees in continuing their careers, among others by paying attention to the following matters: 1 ). Is the worker suitable to be placed in the workplace, 2). Are workers able to carry out their duties well, 3). Does the employee get sympathy from other friends, 4). Are workers able to adapt, 5). Are workers able to maintain a balance between personal and official needs?

Workers will be able to do their job well if there are adequate work support facilities including work environment and work facilities. Work facilities are work tools that include work equipment, materials, and facilities/infrastructure that can affect work implementation by taking into account: 1). Use of work facilities, 2). intellectual

\section{Can bring in the right people to assess and evaluate the training program (invite the right people to attend)}

Training evaluation is a part that should be integral to the overall training program. Training evaluations are arranged systematically to measure the level of success of the training program being organized. One of the evaluation techniques related to behavior is:

a. Select competent instructors (select effective instructors)

b. Using the right technique or method (use effective techniques and aids)

c. Implement the program properly (accomplish the program objectives)

d. Can meet the expectations of all customers (satisfy the participants)

e. Can evaluate programs (evaluate the program)

Table 1. Market share of passenger on international routes 2014-2018 PT Lion Air

\begin{tabular}{llllllll}
\hline No & Operator & 2014 & $\begin{array}{l}\text { Market } \\
\text { Share }\end{array}$ & 2015 & $\begin{array}{l}\text { Market } \\
\text { Share }\end{array}$ & 2016 & $\begin{array}{l}\text { Market } \\
\text { Share }\end{array}$ \\
\hline 1 & PT Lion & 1.461 .780 & $14,26 \%$ & 1.175 .540 & $12,33 \%$ & 1.483 .305 & $14,29 \%$ \\
& Air & & & & & \\
\hline No & Operator & 2017 & $\begin{array}{l}\text { Market } \\
\text { Share }\end{array}$ & 2018 & $\begin{array}{l}\text { Market } \\
\text { Share }\end{array}$ & & \\
& & & & & \\
\hline 1 & PT Lion & 2.234 .970 & $17,07 \%$ & 2.950 .0520 & $21,00 \%$ & & \\
& Air & & & & & & \\
\hline
\end{tabular}

\section{Conclusion}

Based on the results of research and discussion of the flight attendant training program evaluation, a conclusion can be drawn as follows:1) Reaction Stage,,Evaluation at the reaction stage showed that the training program students were very satisfied with the service from the organizing committee and resource persons. What needs to be considered is the completeness of training material (modules) for each student, 2) Learning Stage Evaluation at the learning stage shows that flight attendant students are 
very enthusiastic in participating in the learning process, attitude assessment (behavior, discipline, attendance, cooperation, participation, and responsibility), knowledge (pre-test and post-test scores) and skills are quite satisfying. For the success of all training students passed with certificates. However, it is necessary to improve the ability of participants in implementing the use of emergency tools in an effective way, so that in completing the given task they do not experience obstacles, 3) Behavior Stage, Evaluation at the behavior stage shows the alumni of the program have experienced a behavior change. Discipline in attendance, appearance in dress, independence, attitude in teamwork (teamwork), and speed and accuracy in completing tasks, all of which have changed for the better, 4) Impact Stage, Evaluations at the impact stage indicate changes in performance. Alumni of the program have applied the knowledge that has been received so that their knowledge will increase for the better. Not only the alumni themselves but also their colleagues. The contribution and assistance as well as the role of program alumni in the progress of this training program are very influential in improving student learning outcomes for flight attendants.

\section{Acknowledgment}

We would like to thank all those who have helped to complete this article.

\section{References}

Cross, O., \& Daniel, C. O. (2018). Effects of training on organizational performance. Asian Journal of Business and Management 6(5), 23212802. DOI:10.24203/ajbm.v6i5.548

Diamantidis, A. D., \& Chatzoglou, P. D. (2018). Factors affecting employee performance: an empirical approach. International Journal of Productivity and Performance Management, 68(1), 1-6. DOI:10.1108/IJPPM-01-2018-001

Djaali, \& Muljono, P. (2008). Measurement in the field of Education. PT.Gramedia Pustaka Utama.

Fitzpatrick, J. L., Sanders, J. R., \& Worthen, B. R. (2004). Program evaluation alternative approaches and practical guideline. Pearson Education Inc.

Gronlund, N. E., \& Linn, R. L. (1990). Measurement and evaluation in teaching. macmillan publishing company.

Kaufman, R., \& Thomas, S. (1980). Evaluation without Fear. New Viewpoints.

Kirkpatrick, D. L., \& Kirkpatrick, J. D. (2005). Evaluating training programs the four levels. Berret - Koehler Publishers, Inc.

Nda, M. M., \& Fani, R. Y. (2013). The impact of employee training and development on employee productivity. Global Journal of Commerce \& Management Perspective, 2(6), 91-93.

Ontorael, R., \& Suhadak. (2017). Analysis of the influence of external and internal environmental factors on business performance: a study on Micro Small and Medium Enterprises (MSMES) of food and beverage. Russian Journal of Agricultural and Socio-Economic Sciences, 66(6), 47-56. DOI:10.18551/rjoas.2017-06.05

Pasban, M., Nojedeh, S. H. (2016). A review of the role of human capital in the organization. Procedia - Social and Behavioral Sciences 230. DOI:10.1016/j.sbspro.2016.09.032

Vlad, M., \& Stan, S. (2013). The influence of cultural differences and its application in multinational organizations. Management Dynamics in The Knowledge Economy, 6(3), 405-422. DOI:10.25019/MDKE/6.3.04 